\title{
Insights into Chronic Obstructive Pulmonary Disease Epidemiology, Phenotypes and Outcomes from SPIROMICS
}

Wassim W. Labaki ${ }^{1}$, MD, MS, Fernando J. Martinez ${ }^{1,2}$, MD, MS and MeiLan K. Han ${ }^{1}$, MD, MS

${ }^{1}$ Division of Pulmonary and Critical Care Medicine, University of Michigan, Ann Arbor, MI, USA; ${ }^{2}$ Division of Pulmonary and Critical Care Medicine, Weill Cornell Medical College, New York, NY, USA

\section{ABSTRACT}

SubPopulations and InteRmediate Outcome Measures in COPD Study (SPIROMICS) is a multicentre National Institutes of Health funded cohort study of nearly 3000 never-smokers and ever-smokers ( $\geq 20$ pack-years) with and without chronic obstructive pulmonary disease (COPD). It was designed to help fill gaps in our understanding of the biological complexity and clinical heterogeneity of COPD. The original goals for this study were to identify subgroups of smokers who may benefit from targeted therapies and to discover and validate intermediate biomarker endpoints. Here we review important findings from SPIROMICS over the past five years, including the impact of environmental and occupational exposures on the respiratory health of smokers, the characterisation of symptomatic smokers with preserved pulmonary function and the investigation of several diagnostic and prognostic biomarkers such as airway mucin concentration, functional small airways disease on chest computed tomography and a gene expression signature of interleukin 17A response in airway epithelium. (BRN Rev. 2019;5(4):233-48) Corresponding author: MeiLan K. Han, mrking@umich.edu

Key words: Biomarkers. Chest computed tomography. Chronic obstructive pulmonary disease. Exposures. Phenotypes. 


\section{INTRODUCTION}

Chronic obstructive pulmonary disease (COPD) affects millions of people worldwide and is associated with high morbidity and mortality ${ }^{1-3}$. The complexity of COPD extends far beyond incompletely reversible airflow limitation as reflected by the striking heterogeneity in disease presentation, progression and outcomes ${ }^{4}$. Therefore, the characterisation of distinct clinical phenotypes is paramount to guide the promising field of precision medicine in COPD. SubPopulations and InteRmediate Outcome Measures in COPD Study (SPIROMICS) is a multicentre, National Institutes of Health (NIH)-funded cohort study of nearly 3000 never-smokers and ever-smokers ( $\geq 20$ pack-years) with and without COPD. Table 1 shows the demographic, anthropometric and clinical characteristics of SPIROMICS participants at baseline. The SPIROMICS study was designed to help fill gaps in our understanding of the clinical heterogeneity and biological complexity of $\mathrm{COPD}^{5}$. The original primary aims were to 1) identify subgroups of smokers who may eventually benefit from specific therapies as part of targeted clinical trials, and 2) discover and validate biomarkers to serve as intermediate outcomes in such trials. In this review article, we outline important studies from SPIROMICS that significantly advanced our knowledge of COPD epidemiology, phenotypes and outcomes.

\section{EXPOSURES}

While active smoking is a strong risk factor for COPD development and a well-established predictor of disease progression, the impact of passive smoke exposure, so-called "second-hand smoke", on COPD outcomes has been unclear. In an analysis of 1580 participants with COPD, $27 \%$ reported living with a smoker and $20 \%$ were exposed to second-hand smoke during the past week ${ }^{6}$. Living with a smoker was associated with worse respiratory-related quality of life as measured by the St. George's Respiratory Questionnaire (SGRQ), a higher burden of respiratory symptoms as measured by the COPD Assessment Test (CAT) and a higher incidence of severe COPD exacerbations. Similarly, exposure to second-hand smoke in the past week was associated with worse respiratory symptoms, including chronic productive cough (odds ratio [OR] 1.77; 95\% confidence intervals [CI] 1.33-2.35) and wheezing (OR 1.34; 95\% CI 1.02-1.77), even after adjusting for demographics, lung function, personal smoking status and smoking history. Interestingly, current smokers, obese individuals and participants with Global Initiative for Chronic Obstructive Lung Disease (GOLD) 1-2 grades of spirometry severity were most affected. Therefore, this study not only characterises the harms of passive smoke exposure among individuals with COPD but also identifies subgroups most susceptible to its effects.

Electronic cigarette (e-cigarette) and marijuana use has been increasing among cigarette smokers with or at risk for $\mathrm{COPD}^{7,8}$. The longterm impact of the consumption of such products is still being investigated. A study of 3536 Genetic Epidemiology of COPD (COPDGene) and 1060 SPIROMICS current or former cigarette smokers found that $12-16 \%$ of participants ever used e-cigarettes and that 5\% were current users ${ }^{9}$. Although close to $90 \%$ of ever-users reported using e-cigarettes in order to help decrease or quit consumption of 
TABLE 1. Baseline characteristics of participants

\begin{tabular}{|c|c|c|c|c|}
\hline & $\begin{array}{c}\text { Healthy } \\
\text { never-smokers } \\
\text { (n= 202) }\end{array}$ & $\begin{array}{c}\text { Smokers } \\
\text { without COPD } \\
\text { (n= 941) }\end{array}$ & $\begin{array}{c}\text { Smokers } \\
\text { with mild/moderate } \\
\text { COPD ( } n=1209 \text { ) }\end{array}$ & $\begin{array}{c}\text { Smokers } \\
\text { with severe COPD } \\
\text { (n= 626) }\end{array}$ \\
\hline Age (years) & $56.5(10.2)$ & $60.3(9.7)$ & $65.5(8.2)$ & $64.3(7.8)$ \\
\hline Female & $124(61.4 \%)$ & $493(52.4 \%)$ & $507(41.9 \%)$ & $276(44.1 \%)$ \\
\hline African-American & $46(22.8 \%)$ & $250(26.6 \%)$ & $169(14.0 \%)$ & $111(17.7 \%)$ \\
\hline BMI $\left(\mathrm{kg} / \mathrm{m}^{2}\right)$ & $28.5(5.0)$ & $29.0(5.1)$ & $27.9(5.2)$ & $26.3(5.4)$ \\
\hline Smoking pack-years & 0 & $42.7(24.3)$ & $52.9(29.6)$ & $52.2(23.0)$ \\
\hline Current smoking & 0 & $475(51.0 \%)$ & $460(38.7 \%)$ & $159(25.8 \%)$ \\
\hline $\mathrm{FEV}_{1} / \mathrm{FVC}$ & $0.81(0.05)$ & $0.77(0.05)$ & $0.58(0.08)$ & $0.38(0.10)$ \\
\hline Post-bronchodilator $\mathrm{FEV}_{1} \%$ predicted & $101.8(11.6)$ & $96.8(13.6)$ & $73.9(15.7)$ & $35.5(9.9)$ \\
\hline Chronic bronchitis & $4(2.0 \%)$ & $160(17.5 \%)$ & $281(24.1 \%)$ & $155(25.4 \%)$ \\
\hline
\end{tabular}

Data are expressed as mean (standard deviation) for continuous variables and count (percentage) for categorical ones.

BMI: body mass index; COPD: chronic obstructive pulmonary disease; $\mathrm{FEV}_{1}$ : forced expiratory volume in the first second; FVC: forced vital capacity.

regular cigarettes, these goals were not consistently reached at the 5-year follow-up visit. After adjusting for relevant clinical confounders, ever-use of e-cigarettes was associated with higher SGRQ scores, a higher prevalence of chronic bronchitis and a higher incidence of COPD exacerbations. In contrast, neither current nor former use of marijuana was associated with worse respiratory symptoms though the prevalence of marijuana ever-use was $51 \%{ }^{10}$. Compared to never-users, current and former marijuana users were younger, had better lung function, and were more likely to be men and current smokers of cigarettes. Longitudinal studies are needed to better understand the long-term effects of e-cigarettes and marijuana on the respiratory health, lung function and clinical outcomes of individuals with COPD.

Occupational exposure to vapours, dust, gases or fumes has been recognised as an important risk factor for $\mathrm{COPD}^{11}$. Paulin et al. ${ }^{12}$ further confirmed this relationship as they found that SPIROMICS participants with an intermediate-to-high level of occupational exposures had $44 \%$ higher odds (95\% CI 1.04-1.97) of COPD, even after adjusting for demographics and smoking history. Among individuals with COPD, the presence of such exposures was associated with a higher burden of respiratory symptoms, decreased exertional capacity and a higher incidence of moderate and severe COPD exacerbations. Furthermore, occupational exposures were also associated with radiographic abnormalities on chest computed tomography (CT) including airways disease, air trapping and emphysema ${ }^{13}$. These findings highlight the importance of obtaining a thorough occupational history both in individuals with newly diagnosed and previously established COPD. Outcomes may also be affected by place of residence. In fact, rural residence has been independently associated with an increased risk of moderate COPD exacerbations ${ }^{14}$. Accounting 
for agricultural occupation attenuated but did not fully explain this association, highlighting the need for further investigations into the triggers and mechanisms of COPD exacerbations in residents of rural areas.

\section{SMOKERS WITHOUT AIRFLOW LIMITATION}

While a post-bronchodilator forced expiratory volume in the first second $\left(\mathrm{FEV}_{1}\right) /$ forced vital capacity (FVC) ratio $<0.70$ is currently needed to make a diagnosis of $\mathrm{COPD}^{15}$, many smokers who do not meet this spirometric definition still experience substantial morbidity. A landmark SPIROMICS study showed that half of ever-smokers with preserved pulmonary function reported a significant burden of respiratory symptoms as determined by a CAT score $\geq 10^{16}$. These symptomatic smokers with preserved pulmonary function had a higher rate of respiratory exacerbations than their asymptomatic counterparts $(0.27 \pm 0.67$ versus $0.08 \pm 0.31$ events per year, $\mathrm{p}<0.001$ ) (Fig. 1). This association persisted in adjusted analyses and when cut-offs of 0.65, 0.70 and the lower limit of normal (LLN) were used for $\mathrm{FEV}_{1} / \mathrm{FVC}$ to define obstruction. Notably, close to half of these symptomatic current or former smokers were using bronchodilators and close to a quarter of them were on inhaled corticosteroids, even though no evidence basis for the use of such medications in this patient population exists yet. This analysis helped fulfil one of the primary aims of SPIROMICS, namely to identify a subgroup of patients for targeted enrolment in clinical trials, as it provided the scientific basis for the currently enrolling REdefining THerapy IN Early COPD (RETHINC) trial for the Pulmonary Trials Cooperative (clinicaltrials.gov identifier: NCT02867761). RETHINC is a multicentre, randomised, placebo-controlled trial testing the efficacy of the combined long-acting beta agonist/long-acting muscarinic antagonist (LABA/LAMA) inhaler indacaterol/glycopyrrolate in symptomatic smokers without airflow obstruction. The primary outcome is the proportion of individuals with a 4-point improvement in SGRQ score at 12 weeks.

The cut-off used to identify the presence of an obstructive ventilatory defect on spirometry $\left(\mathrm{FEV}_{1} / \mathrm{FVC}<0.70\right.$ versus $\left.<\mathrm{LLN}\right)$ remains a controversial topic. Pirozzi et al. ${ }^{17}$ sought to understand the characteristics of ever-smokers with $\mathrm{FEV}_{1} / \mathrm{FVC}<0.70$ but $>$ LLN. Compared to ever-smokers and never-smokers with $\mathrm{FEV}_{1} / \mathrm{FVC}>0.70$, this discordant group had a lower post-bronchodilator $\mathrm{FEV}_{1}$ and a greater extent of both emphysema and non-emphysematous air trapping on chest CT. In fact, $44 \%$ of participants in this group had at least one of these radiographic abnormalities. Compared with an $\mathrm{FEV}_{1} / \mathrm{FVC}$ cut-off set at the LLN, a cut-off of 0.70 had a higher sensitivity ( $85 \%$ versus $78 \%$ ) but a lower specificity ( $72 \%$ versus $81 \%$ ) for identifying smokers with radiographic emphysema or gas trapping. This is yet another study that highlights the drawbacks of relying on lung function alone to diagnose COPD as many smokers with normal spirometry have a significant burden of clinical and radiographic disease.

\section{CHEST IMAGING}

Chest CT has become a widely available imaging modality that is increasingly ordered 


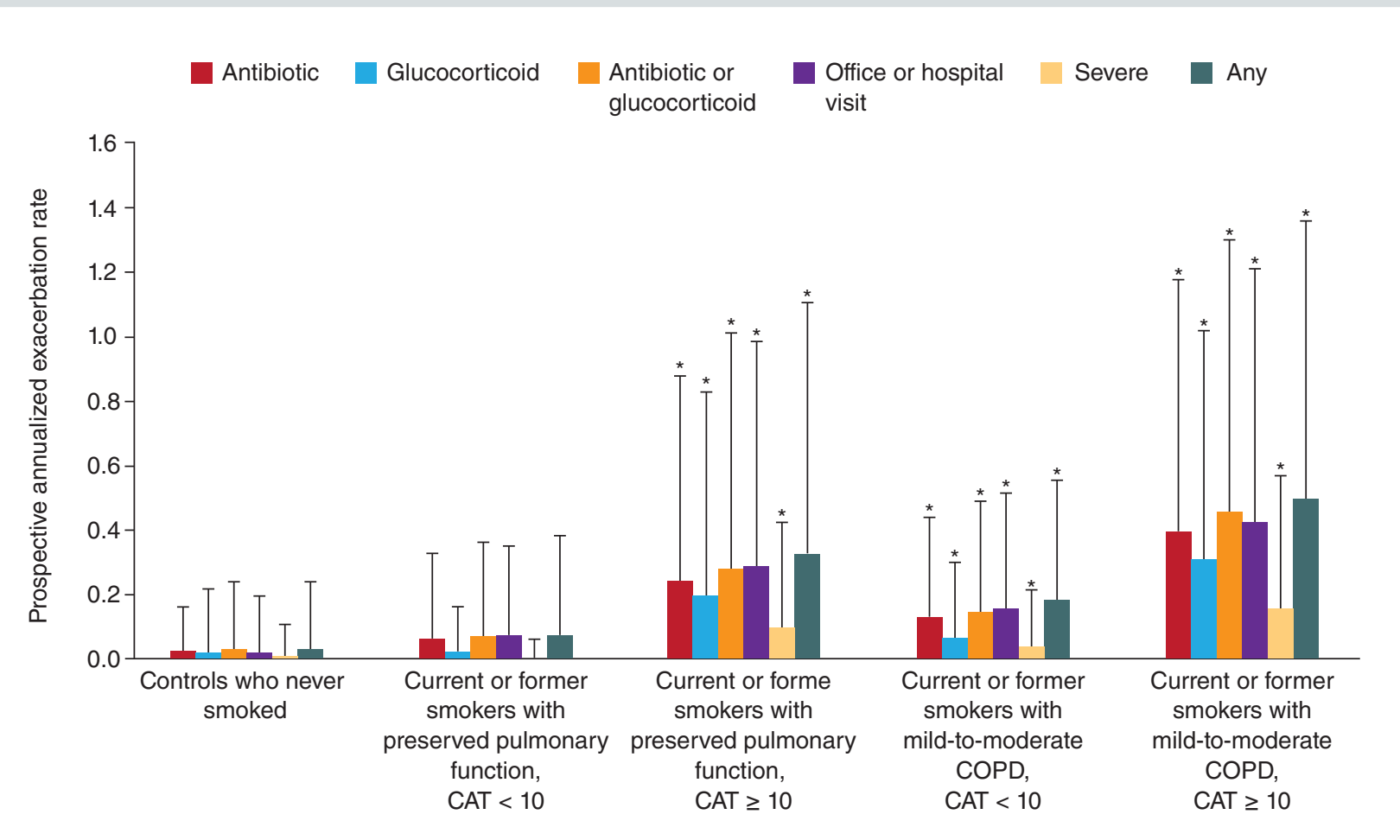

FIGURE 1. Risk of respiratory exacerbations stratified by pulmonary function group and symptomatic status. $T$ bars indicate 1 standard deviation. Asterisks indicate a $\mathrm{p}$ value $<0.05$, with Bonferroni correction for multiple comparisons, for the comparison with current or former smokers with preserved pulmonary function and a CAT score $<10$ (reproduced from Woodruff $P G^{16}$, (C) 2016 Massachusetts Medical Society; reprinted with permission from Massachusetts Medical Society).

CAT: COPD assessment test; COPD: chronic obstructive pulmonary disease.

in the inpatient and outpatient settings to answer a number of clinical questions ranging from ruling out a pulmonary embolism to screening for lung cancer. Beyond providing the requested clinical information, chest CTs contain a wealth of additional data on pulmonary structures (airways, lung parenchyma, pulmonary vasculature), and can also inform comorbidities such as coronary artery disease through coronary artery calcium scoring, osteoporosis through vertebral bone mineral density and frailty through pectoralis muscle area measurement ${ }^{18,19}$. Chest CT is an integral component of the clinical phenotyping of SPIROMICS participants with rigorous imaging protocols implemented through the quantitative CT lung assessment system (QCT-LAS) ${ }^{20}$.

To limit the bias of airway selection, Smith et al. ${ }^{21}$ compared spatially matched airways on chest CTs of participants with COPD and controls enrolled in SPIROMICS and the Multi-Ethnic Study of Atherosclerosis (MESA). They found airway wall areas for central airway segments (generations 1-6 in SPIROMICS and 3-6 in MESA) to be significantly smaller in COPD compared to controls and to become progressively smaller with increasing GOLD grades of spirometry severity. This study underlines the importance of spatial matching 
as selecting airways at random or based on lumen diameter will result in a biased comparison of more proximal airways in COPD to more distal airways in non-COPD. In another CT analysis of the SPIROMICS and MESA cohorts, airway branch variants were found in more than a quarter of the general population $^{22}$. The most common airway branch variant, the presence of an accessory sub-superior airway, was found in $16.0 \%$ of participants and was associated with COPD (pooled OR 1.31, 95\% CI 1.10-1.55 in adjusted analyses) and with shorter central airways and increased emphysema in all lobes. The second most common airway branch variant, the absence of a right medial-basal airway, was found in $6.1 \%$ of participants and was associated with COPD among smokers (pooled OR 1.57; 95\% CI 1.14-2.17 in adjusted analyses), small airway lumen areas in all lobes and with two single nucleotide polymorphisms in the fibroblast growth factor (FGF) 10 gene. These results show that central airway branch variations may represent a heritable risk factor for COPD development and are linked to diffuse pathology in airway architecture and lung parenchyma.

Emphysema can be either visually assessed or quantitatively measured on $\mathrm{CT}^{23,24}$. In an analysis of the SPIROMICS and COPDGene cohorts, higher extent of emphysema on CT (measured as the percentage of lung voxels $<-950$ Hounsfield Units [HU]) was associated with a higher incidence of exacerbations and all-cause mortality (Fig. 2) ${ }^{25}$. In SPIROMICS, compared with participants with $<5 \%$ emphysema, those with $\geq 5 \%$ emphysema had a higher mean exacerbation frequency (0.46 versus 0.21 exacerbations/year; $\mathrm{p}<0.001$ ) and higher mortality (2.66 versus 0.89 deaths per 100 person-years; $p=0.01)$. Results were similar in
COPDGene. Therefore, extent of emphysema on an available CT can be a powerful tool to predict patient outcomes.

Coronary artery disease is a common comorbidity in COPD. In an analysis of 300 SPIROMICS participants, Bhatt et al. ${ }^{26}$ demonstrated that while $\mathrm{FEV}_{1} / \mathrm{FVC}$ was associated with coronary artery calcium (assessed through the Weston visual score), quantitative emphysema and airway wall thickening on CT were not. In subsequent analyses, they found centrilobular, but not paraseptal, emphysema to be associated with coronary artery calcium. Furthermore, they demonstrated that certain plasma biomarkers of inflammation such as C-X-C motif chemokine ligand 9 (CXCL9) mediated the association between airflow obstruction and coronary artery calcium. The importance of this study is twofold: 1) it further characterises the link between COPD and coronary artery disease, and 2) it highlights the utility of visually assessing emphysema subtypes as a complementary tool to quantitatively measuring emphysema.

Parametric response mapping (PRM) is an imaging application that incorporates voxel-based changes in lung parenchyma density between co-registered inspiratory and expiratory chest CTs to classify lung as normal, emphysema ( $<-950 \mathrm{HU}$ on inspiration and $<-856 \mathrm{HU}$ on expiration) and non-emphysematous air trapping ( $>-950 \mathrm{HU}$ on inspiration and $<-856 \mathrm{HU}$ on expiration), a measure of functional small airways disease (fSAD) ${ }^{27}$. Haghighi et al. ${ }^{28}$ identified four different chest imaging clusters among 284 current smokers from SPIROMICS. Cluster 1 was characterised by normal airways and minimal fSAD and emphysema, cluster 2 by airway wall thickening and increased fSAD (mean $8.4 \%$ ), cluster 3 by even higher 

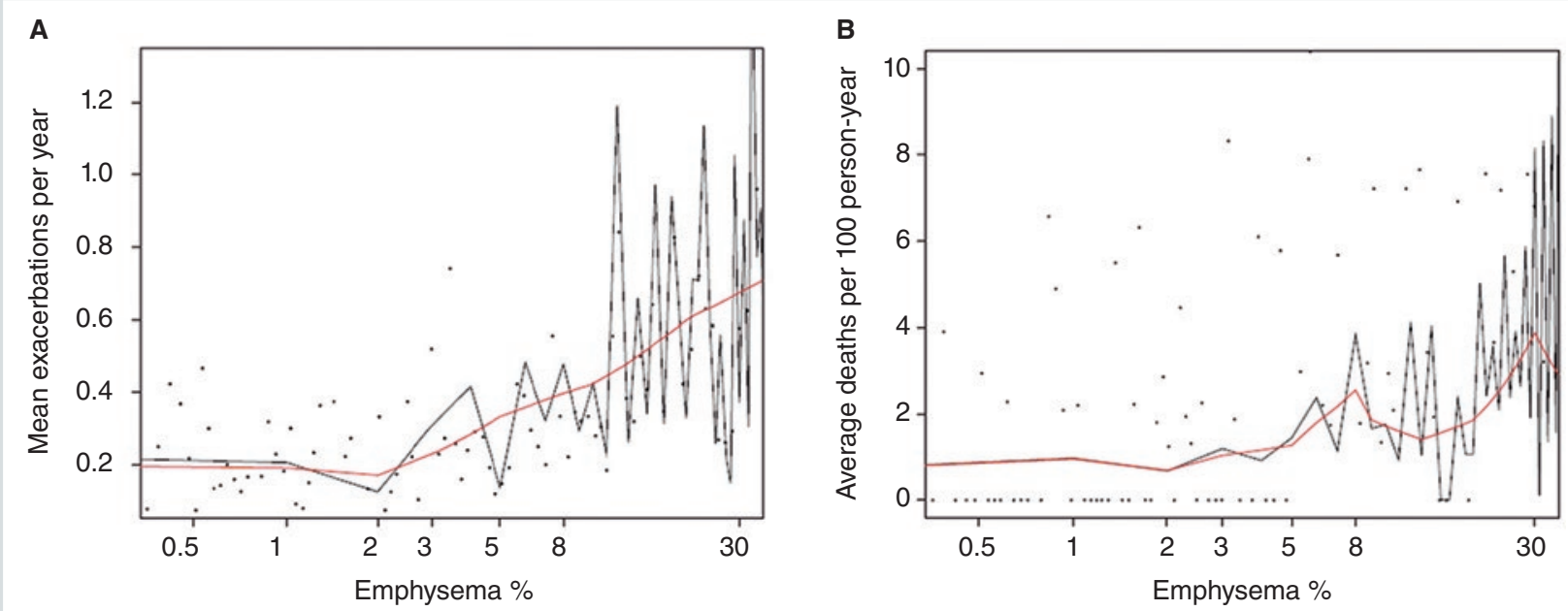

Figure 2. (A) Plot of mean exacerbations per year by percentage emphysema in SPIROMICS. Black dots represent raw averages for exacerbation rates grouped by nearest emphysema percentile. Age-adjusted estimates for average exacerbations per year are shown via linear splines in black and smoothed splines in red. (B) Plot of average deaths per 100 person-years by percentage emphysema in SPIROMICS. Black dots represent raw averages for death rates grouped by nearest emphysema percentile. Age-adjusted estimates for average deaths per 100 person-years are shown via linear splines in black and smoothed splines in red (reproduced from Han $\mathrm{MK}^{25}$ with permission of the American Thoracic Society, (C) 2019 American Thoracic Society).

fSAD (mean 12.3\%) but no airway wall thickening, and cluster 4 by the highest fSAD (mean 34.9\%) and emphysema (13.5\%). As opposed to cluster 1, which had preserved pulmonary function, the other clusters were characterised by airflow obstruction of increasing severity (mean $\mathrm{FEV}_{1} \%$ predicted of $0.80,0.76$ and 0.49 in clusters 2,3 and 4 , respectively). Cluster 4 had the highest mean CAT score and the highest rate of exacerbations. Although this is a smaller study including current smokers only, it highlights the relationship between various CT metrics and clinical variables. Expanding on this relationship, Martinez et al. ${ }^{29}$ found a positive association between fSAD and each of age and FVC, but not $\mathrm{FEV}_{1}$, in a cross-sectional analysis of participants without airflow obstruction. These results shed light on the complex link between ageing and respiratory physiologic changes, and also underscore the potential of PRM for phenotyping individuals without airflow limitation on spirometry. Beyond cross-sectional analyses, PRM metrics can serve as longitudinal imaging biomarkers. Mathematical model simulations showed that fSAD may be a transitional pathologic phase between normal lung and emphysema ${ }^{30}$. Subsequent 5-year longitudinal analyses from COPDGene supported this hypothesis ${ }^{31}$. In summary, these remarkable advances in chest imaging have improved our understanding of COPD and have helped characterise some of its clinical phenotypes. It remains to be seen how they can best be incorporated within routine clinical care and whether they can be leveraged to detect early disease. 


\section{BIOMARKERS}

Complete blood counts are frequently obtained in clinical practice and are readily available for many patients. Both normocytic anaemia and thrombocytosis were found to be independently associated with worse dyspnoea and respiratory-related quality of life in individuals with $\mathrm{COPD}^{32,33}$. In addition, thrombocytosis was linked to a higher likelihood of all COPD exacerbations (adjusted OR 1.5; 95\% CI 1.1-2.0) and severe COPD exacerbations (adjusted OR 1.5; 95\% CI 1.1-2.2) during the preceding year in a combined analysis of the SPIROMICS and COPDGene cohorts ${ }^{33}$. Interestingly, in an observational propensity-score matched analysis from SPIROMICS, aspirin users experienced fewer exacerbations (incidence rate ratio [IRR] $0.78,95 \%$ CI 0.65-0.94) and had a lower burden of respiratory symptoms ${ }^{34}$. These findings deserve further validation in a randomised controlled trial.

The clinical utility of the blood and sputum eosinophil counts in patients with COPD remains controversial ${ }^{35}$. SPIROMICS participants with elevated sputum eosinophils ( $\geq 1.25 \%$ ) had worse lung function, more emphysema and small airways disease on CT and a higher rate of severe exacerbations during the preceding year compared with participants with lower sputum eosinophils $(<1.25 \%)^{36}$. While participants with high blood eosinophils ( $\geq 200$ cells $/ \mu \mathrm{L}$ ) had worse lung function and higher airway wall thickness than those with lower blood eosinophils $(<200$ cells $/ \mu \mathrm{L})$, there were no significant differences between these groups with regards to history of exacerbations and evidence of radiographic emphysema and small airways disease. Although the association between blood and sputum eosinophil counts was statistically significant, it remained relatively weak (area under the curve [AUC] 0.64). Therefore, sputum eosinophils appears to be a better biomarker of disease severity and morbidity than blood eosinophils. Broncho-alveolar lavage (BAL) is another compartment where eosinophil count can be measured. Among individuals with COPD, current smokers had significantly higher BAL eosinophils than former smokers ${ }^{37}$. In contrast, current and former smokers without COPD had similar BAL eosinophil counts. These results suggest that smoking status affects eosinophil recruitment and/or retention in the COPD lung. Of note, BAL eosinophil count was correlated with neither blood nor sputum eosinophil counts.

The generalised and local inflammatory milieu in COPD is reflected in part by disturbed levels of multiple cytokines and chemokines. For example, plasma interleukin 6 (IL-6), a pro-inflammatory cytokine, has been associated with airflow obstruction as well as lung function decline and progression of emphysema over five years of follow-up ${ }^{38}$. Another cytokine of interest is IL-17A whose effects result in the recruitment and activation of neutrophils and macrophages in the airway epithelium ${ }^{39}$. After generating and validating a gene expression signature of IL-17A response in bronchial airway epithelial brushings, Christenson et al. ${ }^{40}$ found this signature to be associated with lower lung function and higher radiographic fSAD in ever-smokers with COPD. When this IL-17A gene expression signature was tested in the Groningen and Leiden Universities study of Corticosteroids in Obstructive Lung Disease (GLUCOLD) study which randomised participants to inhaled corticosteroids (ICS) versus placebo, it was associated 
with decreased response to ICS independent of airway eosinophilic or type 2 inflammation. Therefore, this biomarker identifies a subgroup of COPD patients who may not benefit from traditional ICS therapy but may rather respond to better targeted anti-inflammatory agents. Measurement of serum inflammatory biomarkers may also have a role in smokers without COPD as higher levels of C-reactive protein and soluble tumour necrosis factor (TNF) receptors were associated with a higher burden of respiratory symptoms and a lower 6-minute walking distance in this patient population ${ }^{41}$.

Many patients with COPD experience chronic bronchitis defined as cough with sputum expectoration for at least three months a year during two consecutive years. Airway mucin concentration as measured by size-exclusion chromatography and refractometry appears to be a valid biomarker of chronic bronchitis $^{42}$. It was significantly increased in participants who met the clinical definition of chronic bronchitis compared to those who did not (Fig. 3), in participants with severe COPD compared to never-smoker controls, and in participants with $\geq 2$ respiratory exacerbations per year compared to those with none. Furthermore, higher airway mucin concentration was associated with lower forced expiratory flows in the mid-expiratory phase $\left(\mathrm{FEF}_{25-75 \%}\right)$ on spirometry and with higher fSAD and relative airway wall thickness on $\mathrm{CT}^{43}$.

The quest to find reliable biomarkers predictive of respiratory exacerbations has proven challenging. In an analysis of participants from SPIROMICS and COPDGene assessing the predictive ability of 90 different serum or plasma proteins, there was

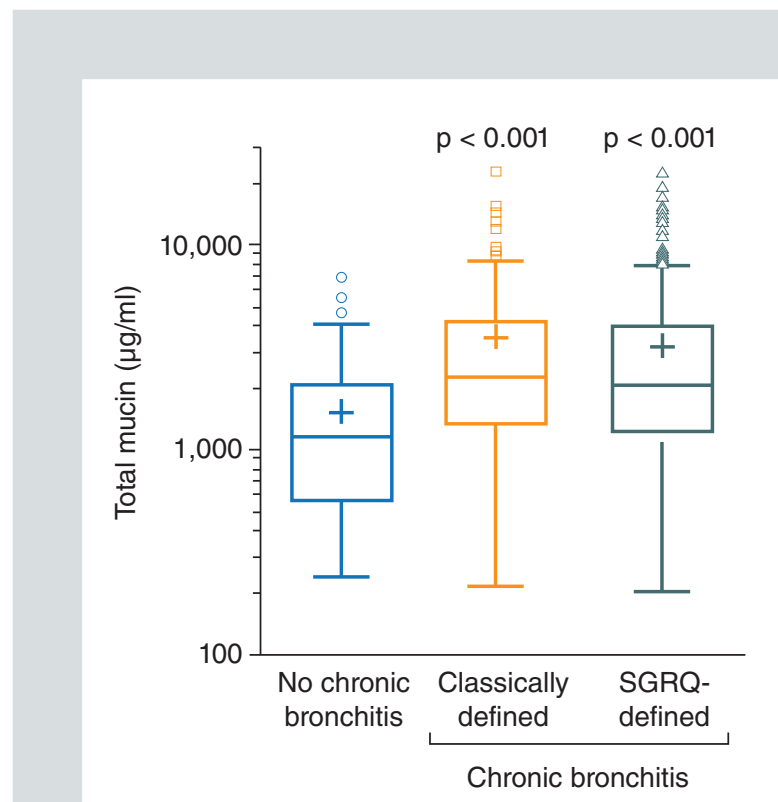

Figure 3. Box plots of total airway mucin concentration in current or former smokers who were identified as having chronic bronchitis by a questionnaire of its classic definition (199 participants), current or former smokers who were identified as having chronic bronchitis by the St. George's Respiratory Questionnaire (SGRO) (382 participants), and controls who had never smoked and were not identified as having chronic bronchitis by either questionnaire. $P$ values are for the comparison with healthy controls who had never smoked /reproduced from Kesimer M42, (C) 2017 Massachusetts Medical Society; reprinted with permission from Massachusetts Medical Society).

minimal replication between the two cohorts ${ }^{44}$. This may be related to the stochastic and highly variable nature of exacerbation events. In an analysis of 1843 SPIROMICS participants with COPD, 49\% experienced at least one exacerbation during three years of follow-up with only $7 \%$ experiencing at least one exacerbation during each year and $2 \%$ experiencing $\geq 2$ exacerbations during each year (Fig. 4$)^{45}$. Instead, an inconsistent pattern of exacerbation occurrences characterised by years with and years without exacerbations was frequent. Another factor complicating the identification of reliable biomarkers to 


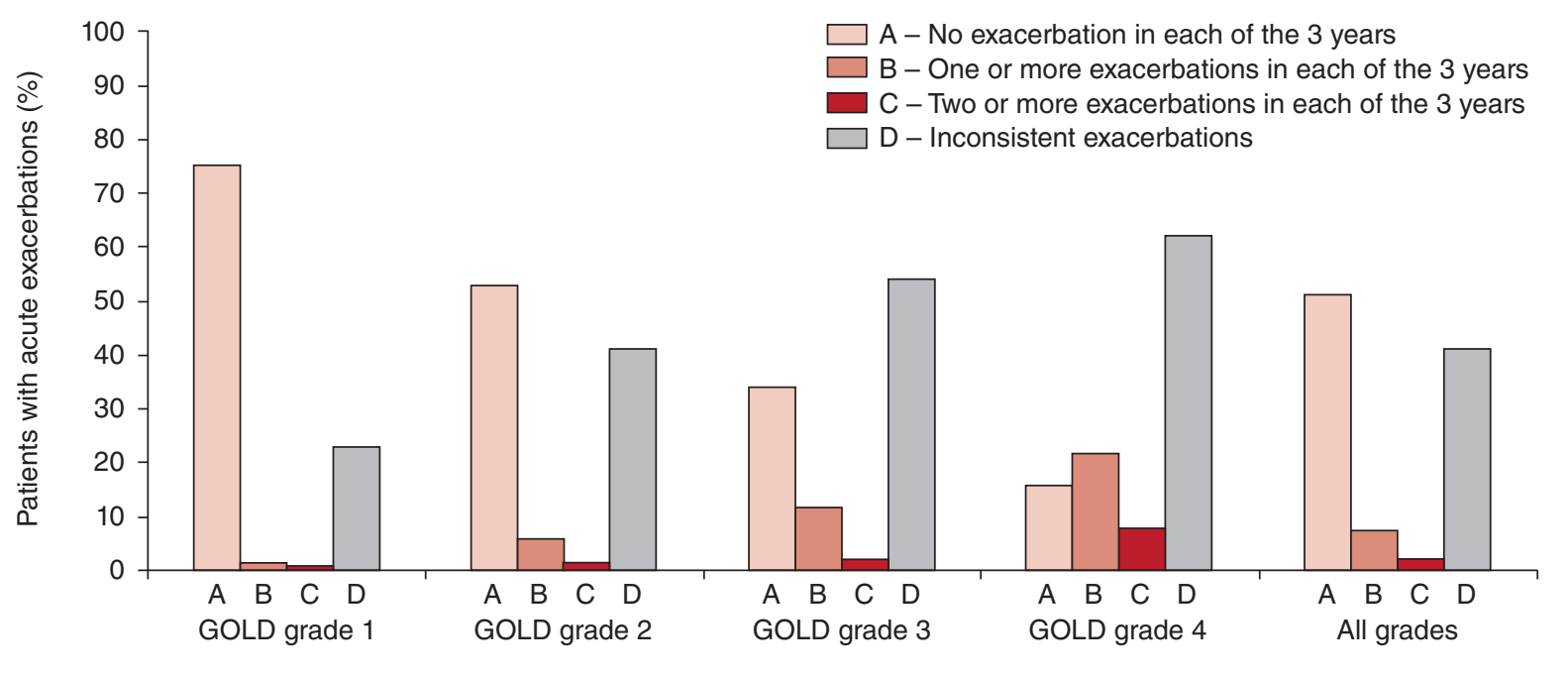

Figure 4. Frequency of acute exacerbations in each of the three years in patients with chronic obstructive pulmonary disease. Data are the proportion of patients with each category of acute exacerbation frequency, by GOLD grade and in the entire group $(n=1105)$ (reprinted from Han $M K^{45}$, (C) 2017 The Lancet, with permission from Elsevier).

GOLD: Global Initiative for Chronic Obstructive Lung Disease.

predict COPD exacerbations is the effect of common genetic polymorphisms on the measurement of blood proteins as demonstrated in a combined analysis of SPIROMICS and COPDGene ${ }^{46}$.

Despite these challenges, a few serum biomarkers were found to be independently associated with incident COPD exacerbations, including low immunoglobin A ( $\operatorname{Ig} \mathrm{A})$, high $\mathrm{N}$-terminal pro-brain natriuretic peptide (NT-proBNP), and high matrix metallopotease 9 (MMP-9). Putcha et al. ${ }^{47}$ found a serum IgA level $\leq 70 \mathrm{mg} / \mathrm{dL}$ to be associated with a higher incidence of exacerbations (IRR 1.71; 95\% CI 1.01-2.87; $\mathrm{p}=0.04$ ) after adjusting for relevant clinical covariates ${ }^{47}$. In a separate SPIROMICS analysis, participants in GOLD grade $\mathrm{D}$ (high symptom and exacerbation burdens) had higher serum NT-proBNP levels compared with participants in GOLD grade B (high symptom but low exacerbation burdens) $(758.4 \text { versus } 574.9 \mathrm{pg} / \mathrm{ml}, \mathrm{p}=0.03)^{48}$. Further, an NT-proBNP level $\geq 900 \mathrm{pg} / \mathrm{ml}$ was independently associated with an increased incidence of COPD exacerbations (IRR 1.62; $95 \%$ 1.19-2.21; $\mathrm{p}=0.002$ ). This association was maintained in participants with and without a self-reported history of coronary artery disease, myocardial infarction and congestive heart failure. In adjusted models, Wells et al. ${ }^{49}$ found an association between elevated plasma MMP-9 (defined as $>95^{\text {th }}$ percentile of values from healthy controls) and increased odds of exacerbations (OR 1.71; 95\% CI 1.00-2.90; $\mathrm{p}=0.049$ ), frequency of exacerbations (IRR 1.45; 95\% CI 1.23-1.70; $p<0.001$ ) and shorter time to first exacerbation (21.7 versus 31.7 months; $p=0.015$ ). Importantly, these results were replicated in participants 
from the COPDGene cohort. In summary, low IgA, high NT-proBNP and high MMP-9 likely reflect increased susceptibility to exacerbation events through impaired immunity, clinical or subclinical cardiac dysfunction and increased inflammation, respectively. It remains to be determined whether targeted therapies (such as intravenous immunoglobulin replacement or MMP-9 modulators) and interventions (such as more aggressive screening for cardiovascular disease) can reduce exacerbation frequency in select patients with COPD.

In a genome-wide association study (GWAS) of 1645 non-Hispanic white participants enrolled in SPIROMICS, a functional rare variant in the SERPINA1 gene (rs28929474: Glu342Lys) was associated with lower $\mathrm{FEV}_{1} /$ $\mathrm{FVC}$ and $\mathrm{FEV}_{1}{ }^{50}$. In a model including age, sex and smoking pack-years, the top 10 single nucleotide polymorphisms associated with $\mathrm{FEV}_{1}$ (including the aforementioned SERPINA1 variant) explained $8.6 \%$ of the variance of $\mathrm{FEV}_{1} / \mathrm{FVC}$. This study provides additional evidence of the genetic contributions to COPD pathogenesis and underlines the potential of combining genetic and clinical data.

\section{COMORBIDITIES AND QUALITY OF LIFE}

Comorbidities are common in COPD and include coronary artery disease, osteoporosis, depression, anxiety and obstructive sleep apnoea. A simple count of comorbidities performed as well as weighted comorbidity scores to predict the modified medical research council (mMRC) score of dyspnoea, the SGRQ score, the 6-minute walking distance and the risk of exacerbations, even after accounting for demographics, smoking history and lung function ${ }^{51}$. Zeidler et al. $^{52}$ found that poor sleep quality as measured by the Pittsburgh Sleep Quality Index was associated with worse quality of life among patients with COPD beyond their risk for obstructive sleep apnoea ${ }^{52}$. As more than half of participants reported poor sleep, intervening on this reversible problem in clinical practice has the potential to significantly improve lives of patients with COPD. Dyspnoea severity also expectedly contributes to the quality of life of individuals with COPD. However, for the same degree of dyspnoea, middle-age patients with COPD (50-64 years) have higher SGRQ scores (i.e., worse health quality of life) than their older counterparts (65-80 years), which further highlights the importance of taking into account age-related differences when delivering individualized care in everyday practice $^{53}$.

\section{INHALER THERAPY}

The GOLD provides guidance on management of inhaler therapy for COPD patients based on its ABCD staging schema. Ghosh et al. ${ }^{54}$ assessed the alignment of inhaler therapy prescribed to SPIROMICS participants by their medical providers between 2010 and 2016 with 2011 GOLD recommendations ${ }^{54}$. They found that close to half of participants were not being managed in line with GOLD strategies (Fig. 5A). Of these, 54\% were under-treated and $46 \%$ were over-treated (Fig. 5B). Under-treatment was mainly due to lack of long-acting inhalers in GOLD grade D, while over-treatment was mostly attributed 
A

Proportion of SPIROMICS participants aligning with GOLD 1st or 2nd line recommendations

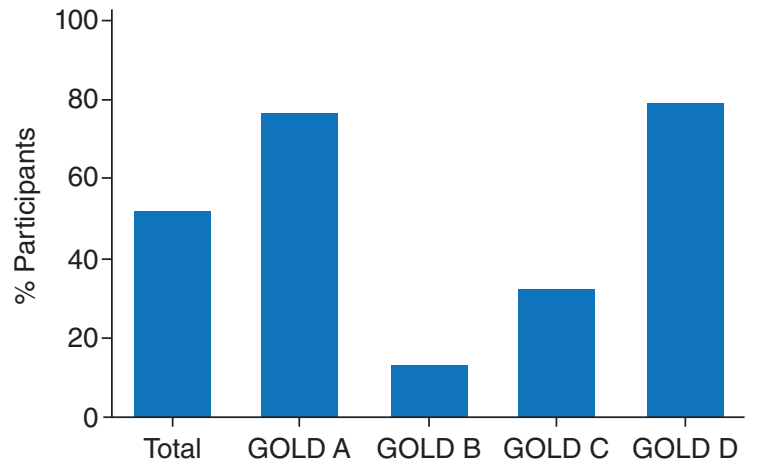

B

Overuse and underuse among SPIROMICS participants not aligning with GOLD recommendations

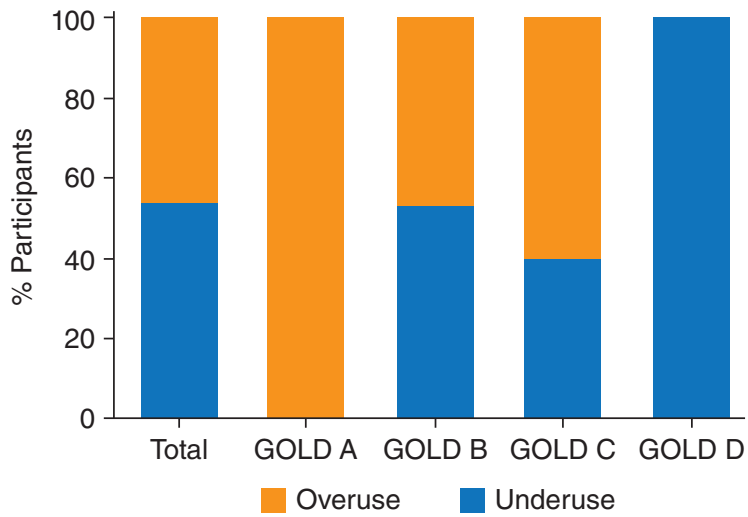

FIgURE 5. (A) Proportion of SPIROMICS participants aligning with Global Initiative for Chronic Obstructive Lung Disease (GOLD) first- or second-line treatment recommendations, stratified by baseline GOLD group. (B) Distribution of overuse and underuse among SPIROMICS participants not aligning with GOLD first- or second-line treatment recommendations, stratified by baseline GOLD group (reproduced from Ghosh $S^{54}$ with permission of the American Thoracic Society, (C) 2019 American Thoracic Society).

to the use of ICS-containing inhalers when not indicated. Both under- and over-treatment may result in higher morbidity in patients with COPD as the former may hinder the achievement of important patient-centred outcomes such as symptom relief and reduction of exacerbation frequency, while the latter may lead to unnecessary adverse events such as pneumonia ${ }^{55}$ and non-tuberculous mycobacteria infection ${ }^{56}$. Therefore, a better understanding of the barriers limiting the widespread adoption of GOLD recommendations in clinical practice warrants further study.

\section{CONCLUSIONS}

Over the past five years, SPIROMICS has generated significant knowledge on the clinical phenotypes of COPD through the identification of distinct subgroups and the investigation of various chest and imaging biomarkers. Table 2 summarises the major findings of SPIROMICS to date and highlights important gaps in our understanding of COPD epidemiology, pathogenesis and progression. The benefits of lungvolume-reduction surgery in specific patients with emphysema and of roflumilast in frequently exacerbating individuals with chronic bronchitis have established the feasibility and potential of precision medicine in $\mathrm{COPD}^{57,58}$. However, beyond these select therapies, most patients receive the same treatments, largely consisting of inhaled bronchodilators and corticosteroids. Therefore, therapies targeted towards specific underlying pathologic pathways remain sorely needed in COPD. To this end, SPIROMICS II will extend follow-up of previously enrolled participants with aims to define the natural 
TABLE 2. Summary of main SPIROMICS findings and remaining unanswered questions

\begin{tabular}{|c|c|c|}
\hline Topic & SPIROMICS findings & Research gaps \\
\hline Exposures & $\begin{array}{l}\text { - Second-hand smoke exposure and ever-use of e-cigarettes are associat- } \\
\text { ed with a higher burden of respiratory symptoms in individuals with COPD } \\
\text { - Occupational exposure to vapours, dust, gases or fumes in COPD patients } \\
\text { is associated with more respiratory symptoms, a higher incidence of } \\
\text { COPD exacerbations, and more airways disease and emphysema on } \\
\text { chest CT }\end{array}$ & $\begin{array}{l}\text { - Long-term effects of e-cigarette use on the } \\
\text { respiratory health, lung function and clinical } \\
\text { outcomes of individuals with COPD remain } \\
\text { to be determined }\end{array}$ \\
\hline $\begin{array}{l}\text { Smokers without } \\
\text { airflow } \\
\text { obstruction }\end{array}$ & $\begin{array}{l}\text { - Symptomatic smokers with preserved pulmonary function experience } \\
\text { significant respiratory morbidity and are often placed on inhaled } \\
\text { bronchodilators and/or corticosteroids } \\
\text { - Compared with an FEV1/FVC cut-off set at the lower limit of normal, a } \\
\text { cut-off of } 0.7 \text { has a higher sensitivity but lower specificity for identifying } \\
\text { smokers with radiologic emphysema or air trapping }\end{array}$ & $\begin{array}{l}\text { - Evidence-based clinical management strate- } \\
\text { gies need to be established for symptomatic } \\
\text { smokers without airflow obstruction. The } \\
\text { ongoing randomized clinical trial RETHINC } \\
\text { (NCT02867761) will help inform this gap }\end{array}$ \\
\hline Chest imaging & $\begin{array}{l}\text { - Central airway branch variations may represent a heritable risk factor for } \\
\text { COPD pathogenesis } \\
\text { - Higher extent of emphysema on chest CT is associated with a higher } \\
\text { incidence of respiratory exacerbations and all-cause mortality } \\
\text { - Distinct clinical clusters can be identified based on the severity of } \\
\text { emphysema and large and small airways disease on chest CT in patients } \\
\text { with COPD }\end{array}$ & $\begin{array}{l}\text { - Additional research is needed to determine } \\
\text { how best to incorporate chest imaging into } \\
\text { routine clinical care of patients with COPD } \\
\text { and how to leverage its potential in order to } \\
\text { detect early disease in individuals at risk }\end{array}$ \\
\hline Biomarkers & $\begin{array}{l}\text { - Anaemia and thrombocytosis are associated with worse dyspnoea and } \\
\text { respiratory-related quality of life in COPD } \\
\text { - Sputum eosinophils may be a better biomarker of COPD severity and } \\
\text { morbidity compared to blood eosinophils } \\
\text { - A gene expression signature of IL-17A response in bronchial airway } \\
\text { epithelial brushings is associated with lower lung function, more } \\
\text { radiologic small airways disease and decreased response to inhaled } \\
\text { corticosteroids } \\
\text { - Airway mucin concentration appears to be a valid biomarker of chronic } \\
\text { bronchitis } \\
\text { - Finding reliable biomarkers predictive of COPD exacerbations is } \\
\text { challenging, likely partially due to the high variability within and between } \\
\text { individuals in the frequency of these events } \\
\text { - Low IgA, high NT-proBNP and high MMP-9 measured in the blood have } \\
\text { independently been associated with an increased risk of incident COPD } \\
\text { exacerbations }\end{array}$ & $\begin{array}{l}\text { - It remains to be determined how to use } \\
\text { biomarkers to guide clinical management } \\
\text { and improve long-term outcomes of patients } \\
\text { with COPD } \\
\text { - Identifying new potential therapeutic targets } \\
\text { related to these biomarkers also warrants } \\
\text { further investigation }\end{array}$ \\
\hline $\begin{array}{l}\text { Comorbidities and } \\
\text { quality of life }\end{array}$ & $\begin{array}{l}\text { - Poor sleep quality is associated with worse quality of life in patients with } \\
\text { COPD beyond their risk for obstructive sleep apnoea } \\
\text { - For the same severity of dyspnoea, perception of health status is worse in } \\
\text { middle-age individuals with COPD compared to older ones }\end{array}$ & $\begin{array}{l}\text { - A complete understanding of the complex } \\
\text { respiratory physiology at the intersection of } \\
\text { sleep and COPD is still lacking } \\
\text { - Factors affecting quality of life in COPD } \\
\text { need to be further studied by age category, } \\
\text { sex and even culture }\end{array}$ \\
\hline Inhaler therapy & $\begin{array}{l}\text { - Inhaler management in about } 50 \% \text { of patients with COPD is not aligned } \\
\text { with GOLD recommendations, with half of these being under-treated and } \\
\text { the other half being over-treated }\end{array}$ & $\begin{array}{l}\text { - Barriers limiting the application of GOLD } \\
\text { recommendations in real-world clinical } \\
\text { settings need to be identified }\end{array}$ \\
\hline
\end{tabular}

BNP: brain natriuretic peptide; COPD: chronic obstructive pulmonary disease; CT: computed tomography; GOLD: Global Initiative for Chronic Obstructive Lung Disease; IgA: immunoglobin A; IL: interleukin; MMP: matrix metallopotease; RETHINC: REdefining THerapy In Early COPD.

history of symptomatic smokers without airflow obstruction, elucidate the molecular phenotypes behind clinical and radiographic disease progression, and further characterise the triggers and host inflammatory responses associated with COPD exacerbations. Such knowledge will help expand our understanding of the complex heterogeneity of COPD to advance precision medicine and improve clinical outcomes. 


\section{ACKNOWLEDGMENTS}

The authors thank the SPIROMICS participants and participating physicians, investigators and staff for making this research possible. More information about the study and how to access SPIROMICS data is at www.spiromics.org. We would like to acknowledge the following current and former investigators of the SPIROMICS sites and reading centres: Neil E Alexis, MD; Wayne $\mathrm{H}$ Anderson, PhD; Mehrdad Arjomandi, MD; Igor Barjaktarevic, $\mathrm{MD}$, PhD; R Graham Barr, MD, DrPH; Lori A Bateman, MSc; Surya P Bhatt, MD; Eugene R Bleecker, MD; Richard C Boucher, MD; Russell P Bowler, MD, PhD;; Stephanie A Christenson, $\mathrm{MD}$; Alejandro P Comellas, MD; Christopher B Cooper, MD, PhD; David J Couper, $\mathrm{PhD}$; Gerard J Criner, MD; Ronald G Crystal, MD; Jeffrey L Curtis, MD; Claire M Doerschuk, MD; Mark T Dransfield, MD; Brad Drummond, MD; Christine M Freeman, PhD; Craig Galban, PhD; MeiLan K Han, MD, MS; Nadia N Hansel, MD, MPH; Annette T Hastie, PhD; Eric A Hoffman, PhD; Yvonne Huang, MD; Robert J Kaner, MD; Richard E Kanner, MD; Eric C Kleerup, MD; Jerry A Krishnan, MD, PhD; Lisa M LaVange, PhD; Stephen C Lazarus, MD; Fernando J Martinez, MD, MS; Deborah A Meyers, PhD; Wendy C Moore, MD; John D Newell Jr, MD; Robert Paine, III, MD; Laura Paulin, MD, MHS; Stephen P Peters, MD, PhD; Cheryl Pirozzi, MD; Nirupama Putcha, MD, MHS; Elizabeth C Oelsner, MD, MPH; Wanda K $\mathrm{O}^{\prime} \mathrm{Neal}$, PhD; Victor E Ortega, MD, PhD; Sanjeev Raman, MBBS, MD; Stephen I. Rennard, MD; Donald P Tashkin, MD; J Michael Wells, MD; Robert A Wise, MD; and Prescott G Woodruff, MD, MPH. The project officers from the Lung Division of the National Heart, Lung, and Blood Institute were Lisa Postow, $\mathrm{PhD}$, and Lisa Viviano, BSN.

\section{SOURCES OF SUPPORT}

SPIROMICS was supported by contracts from the NIH/NHLBI (HHSN268200900013C, HHSN268200900014C, HHSN268200900015C, HHSN268200900016C, HHSN268200900017C, HHSN268200900018C, HHSN268200900019C, HHSN268200900020C), and a grant from the NIH/NHLBI (U01 HL137880), and supplemented by contributions made through the Foundation for the NIH and the COPD Foundation from AstraZeneca/MedImmune; Bayer; Bellerophon Therapeutics; Boehringer-Ingelheim Pharmaceuticals, Inc.; Chiesi Farmaceutici S.p.A.; Forest Research Institute, Inc;; GlaxoSmithKline; Grifols Therapeutics, Inc.; Ikaria, Inc.; Novartis Pharmaceuticals Corporation; Nycomed $\mathrm{GmbH}$; ProterixBio; Regeneron Pharmaceuticals, Inc.; Sanofi; Sunovion; Takeda Pharmaceutical Company; Theravance Biopharma; and Mylan.

This manuscript was also supported by National Institutes of Health grants T32HL007749 (WWL), R01HL122438 (MKH) and K24HL138188 $(\mathrm{MKH})$.

\section{DISCLOSURES}

Dr. Labaki has nothing to disclose. Dr. Martinez reports personal fees, non-financial support and other from AstraZeneca, Boehringer Ingelheim and ProterrixBio; personal fees and non-financial support from Genentech, GlaxoSmithKline, Inova Fairfax Health System, 
Miller Communications, National Association for Continuing Education, Novartis, Pearl Pharmaceuticals, PeerView Communications, Prime Communications, Puerto Rican Respiratory Society, Chiesi, Sunovion, Theravance, Potomac, University of Alabama Birmingham, Physicians Education Resource and Canadian Respiratory Network; personal fees and other from Patara/Respivant, Teva and Dartmouth; personal fees from Columbia University, MD Magazine, Methodist Hospital Brooklyn, New York University, UpToDate, WebMD/MedScape, American Thoracic Society, Rockpointe, Rare Disease Healthcare Communications, France Foundation and Physicians Education Resource; non-financial support from Gilead, Nitto and Zambon; other from Afferent/Merck, Biogen, Veracyte, Prometic, Bayer, Bridge Biotherapeutics, ProMedior and Gala; and grants from NIH; all outside the submitted work. Dr. Han reports grants from NIH, during the conduct of the study; personal fees from GSK, Boehringer Ingelheim, AstraZeneca and other from Sunovion and Novartis, outside the submitted work.

\section{REFERENCES}

1. Adeloye D, Chua S, Lee C et al. Global and regional estimates of COPD prevalence: Systematic review and meta-analysis. J Glob Health. 2015;5: 020415.

2. Global Burden of Disease Study C. Global, regional, and national incidence, prevalence, and years lived with disability for 301 acute and chronic diseases and injuries in 188 countries, 1990-2013: a systematic analysis for the Global Burden of Disease Study 2013. Lancet. 2015;386:743-800.

3. Lozano R, Naghavi M, Foreman $\mathrm{K}$ et al. Global and regional mortality from 235 causes of death for 20 age groups in 1990 and 2010: a systematic analysis for the Global Burden of Disease Study 2010. Lancet. 2012;380: 2095-2128.

4. Duffy S, Weir M, Criner GJ. The complex challenge of chronic obstructive pulmonary disease. Lancet Respir Med. 2015;3:917-9.

5. Couper D, LaVange LM, Han M et al. Design of the Subpopulations and Intermediate Outcomes in COPD Study (SPIROMICS). Thorax. 2014;69: 491-4.

6. Putcha N, Barr RG, Han MK et al. Understanding the impact of second-hand smoke exposure on clinical outcomes in participants with COPD in the SPIROMICS cohort. Thorax. 2016;71:411-20.
7. Pearson JL, Richardson A, Niaura RS, Vallone DM, Abrams DB. e-Cigarette awareness, use, and harm perceptions in US adults. Am J Public Health. 2012;102:1758-66.

8. Lloyd SL, Striley CW. Marijuana Use Among Adults 50 Years or Older in the 21st Century. Gerontol Geriatr Med. 2018;4:2333721418781668.

9. Bowler RP, Hansel NN, Jacobson S et al. Electronic Cigarette Use in US Adults at Risk for or with COPD: Analysis from Two Observational Cohorts. J Gen Intern Med. 2017;32:1315-22.

10. Morris MA, Jacobson SR, Kinney GL et al. Marijuana Use Associations with Pulmonary Symptoms and Function in Tobacco Smokers Enrolled in the Subpopulations and Intermediate Outcome Measures in COPD Study (SPIROMICS). Chronic Obstr Pulm Dis. 2018;5:46-56.

11. Eisner MD, Anthonisen N, Coultas D et al. An official American Thoracic Society public policy statement: Novel risk factors and the global burden of chronic obstructive pulmonary disease. Am J Respir Crit Care Med. 2010;182:693-718.

12. Paulin LM, Diette GB, Blanc PD et al. Occupational exposures are associated with worse morbidity in patients with chronic obstructive pulmonary disease. Am J Respir Crit Care Med. 2015;191:557-65.

13. Paulin LM, Smith BM, Koch A et al. Occupational Exposures and Computed Tomographic Imaging Characteristics in the SPIROMICS Cohort. Ann Am Thorac Soc. 2018;15:1411-19.

14. Burkes RM, Gassett AJ, Ceppe AS et al. Rural Residence and COPD Exacerbations: Analysis of the SPIROMICS Cohort. Ann Am Thorac Soc. 2018.

15. Vogelmeier CF, Criner GJ, Martinez FJ et al. Global Strategy for the Diagnosis, Management, and Prevention of Chronic Obstructive Lung Disease 2017 Report. GOLD Executive Summary. Am J Respir Crit Care Med. 2017; 195:557-82.

16. Woodruff PG, Barr RG, Bleecker E et al. Clinical Significance of Symptoms in Smokers with Preserved Pulmonary Function. N Engl J Med. 2016;374: 1811-21.

17. Pirozzi CS, Gu T, Quibrera PM et al. Heterogeneous burden of lung disease in smokers with borderline airflow obstruction. Respir Res. 2018;19:223.

18. Labaki WW, Martinez CH, Martinez FJ et al. The Role of Chest Computed Tomography in the Evaluation and Management of the Patient with Chronic Obstructive Pulmonary Disease. Am J Respir Crit Care Med. 2017;196:1372-9.

19. Bhatt SP, Washko GR, Hoffman EA et al. Imaging Advances in Chronic Obstructive Pulmonary Disease. Insights from the Genetic Epidemiology of Chronic Obstructive Pulmonary Disease (COPDGene) Study. Am J Respir Crit Care Med. 2019;199:286-301.

20. Sieren JP, Newell JD, Jr., Barr RG et al. SPIROMICS Protocol for Multicenter Quantitative Computed Tomography to Phenotype the Lungs. Am J Respir Crit Care Med. 2016;194:794-806.

21. Smith BM, Hoffman EA, Rabinowitz D et al. Comparison of spatially matched airways reveals thinner airway walls in COPD. The Multi-Ethnic Study of Atherosclerosis (MESA) COPD Study and the Subpopulations and Intermediate Outcomes in COPD Study (SPIROMICS). Thorax. 2014;69: 987-96.

22. Smith BM, Traboulsi H, Austin JHM et al. Human airway branch variation and chronic obstructive pulmonary disease. Proc Natl Acad Sci U S A. 2018;115:E974-E981.

23. Lynch DA, Austin JH, Hogg JC et al. CT-Definable Subtypes of Chronic Obstructive Pulmonary Disease: A Statement of the Fleischner Society. Radiology. 2015;277:192-205.

24. Muller NL, Staples CA, Miller RR, Abboud RT. "Density mask". An objective method to quantitate emphysema using computed tomography. Chest. 1988;94:782-787.

25. Han MK, Tayob N, Murray S et al. Association between Emphysema and Chronic Obstructive Pulmonary Disease Outcomes in the COPDGene and SPIROMICS Cohorts: A Post Hoc Analysis of Two Clinical Trials. Am J Respir Crit Care Med. 2018;198:265-7.

26. Bhatt SP, Nath HP, Kim YI et al. Centrilobular emphysema and coronary artery calcification: mediation analysis in the SPIROMICS cohort. Respir Res. 2018;19:257. 
27. Galban CJ, Han MK, Boes JL et al. Computed tomography-based biomarker provides unique signature for diagnosis of COPD phenotypes and disease progression. Nat Med. 2012;18:1711-5.

28. Haghighi B, Choi S, Choi J et al. Imaging-based clusters in current smokers of the COPD cohort associate with clinical characteristics: the SubPopulations and Intermediate Outcome Measures in COPD Study (SPIROMICS). Respir Res. 2018;19:178.

29. Martinez $\mathrm{CH}$, Diaz AA, Meldrum $\mathrm{C}$ et al. Age and Small Airway Imaging Abnormalities in Subjects with and without Airflow Obstruction in SPIROMICS. Am J Respir Crit Care Med. 2017;195:464-72.

30. Boes JL, Hoff BA, Bule M et al. Parametric response mapping monitors temporal changes on lung CT scans in the subpopulations and intermediate outcome measures in COPD Study (SPIROMICS). Acad Radiol. 2015; 22:186-94.

31. Labaki WW, Gu T, Murray S et al. Voxel-Wise Longitudinal Parametric Response Mapping Analysis of Chest Computed Tomography in Smokers. Acad Radiol. 2019;26:217-23.

32. Putcha N, Fawzy A, Paul GG et al. Anemia and Adverse Outcomes in a Chronic Obstructive Pulmonary Disease Population with a High Burden of Comorbidities. An Analysis from SPIROMICS. Ann Am Thorac Soc. 2018; 15:710-7.

33. Fawzy A, Putcha N, Paulin LM et al. Association of thrombocytosis with COPD morbidity: the SPIROMICS and COPDGene cohorts. Respir Res. 2018;19:20.

34. Fawzy A, Putcha N, Aaron CP et al. Aspirin Use and Respiratory Morbidity in COPD: A Propensity Score-Matched Analysis in Subpopulations and Intermediate Outcome Measures in COPD Study. Chest. 2019;155:519-27.

35. Celli BR, Criner GJ. Using the Peripheral Blood Eosinophil Count to Manage Patients with Chronic Obstructive Pulmonary Disease. Ann Am Thorac Soc. 2019;16:301-3.

36. Hastie AT, Martinez FJ, Curtis JL et al. Association of sputum and blood eosinophil concentrations with clinical measures of COPD severity: an analysis of the SPIROMICS cohort. Lancet Respir Med. 2017;5:956-67.

37. Martinez CH, Li SX, Hirzel AJ et al. Alveolar eosinophilia in current smokers with chronic obstructive pulmonary disease in the SPIROMICS cohort. J Allergy Clin Immunol. 2018;141:429-32.

38. Bradford E, Jacobson S, Varasteh J et al. The value of blood cytokines and chemokines in assessing COPD. Respir Res. 2017;18:180.

39. Pridgeon C, Bugeon L, Donnelly L et al. Regulation of IL-17 in chronic inflammation in the human lung. Clin Sci (Lond). 2011;120:515-24.

40. Christenson SA, van den Berge M, Faiz A et al. An airway epithelial IL-17A response signature identifies a steroid-unresponsive COPD patient subgroup. J Clin Invest. 2019;129:169-81.

41. Garudadri S, Woodruff PG, Han MK et al. Systemic Markers of Inflammation in Smokers With Symptoms Despite Preserved Spirometry in SPIROMICS. Chest. 2019.

42. Kesimer M, Ford AA, Ceppe A et al. Airway Mucin Concentration as a Marker of Chronic Bronchitis. N Engl J Med. 2017;377:911-22.
43. Kesimer M, Smith BM, Ceppe A et al. Mucin Concentrations and Peripheral Airway Obstruction in Chronic Obstructive Pulmonary Disease. Am J Respir Crit Care Med. 2018;198:1453-6.

44. Keene JD, Jacobson S, Kechris K et al. Biomarkers Predictive of Exacerbations in the SPIROMICS and COPDGene Cohorts. Am J Respir Crit Care Med. 2017;195:473-81.

45. Han MK, Quibrera PM, Carretta EE et al. Frequency of exacerbations in patients with chronic obstructive pulmonary disease: an analysis of the SPIROMICS cohort. Lancet Respir Med. 2017;5:619-26.

46. Sun W, Kechris K, Jacobson S et al. Common Genetic Polymorphisms Influence Blood Biomarker Measurements in COPD. PLoS Genet. 2016;12: e1006011.

47. Putcha N, Paul GG, Azar A et al. Lower serum IgA is associated with COPD exacerbation risk in SPIROMICS. PLoS One. 2018;13:e0194924.

48. Labaki WW, Xia M, Murray S et al. NT-proBNP in stable COPD and future exacerbation risk: Analysis of the SPIROMICS cohort. Respir Med. 2018; 140:87-93.

49. Wells JM, Parker MM, Oster RA et al. Elevated circulating MMP-9 is linked to increased COPD exacerbation risk in SPIROMICS and COPDGene. JCI Insight. 2018;3.

50. Li X, Ortega VE, Ampleford EJ et al. Genome-wide association study of lung function and clinical implication in heavy smokers. BMC Med Genet. 2018;19:134.

51. Putcha N, Puhan MA, Drummond MB et al. A simplified score to quantify comorbidity in COPD. PLoS One. 2014;9:e114438.

52. Zeidler MR, Martin JL, Kleerup EC et al. Sleep disruption as a predictor of quality of life among patients in the subpopulations and intermediate outcome measures in COPD study (SPIROMICS). Sleep. 2018;41.

53. Martinez CH, Diaz AA, Parulekar AD et al. Age-Related Differences in Health-Related Quality of Life in COPD: An Analysis of the COPDGene and SPIROMICS Cohorts. Chest. 2016;149:927-35.

54. Ghosh S, Anderson WH, Putcha N et al. Alignment of Inhaled Chronic Obstructive Pulmonary Disease Therapies with Published Strategies. Analysis of the Global Initiative for Chronic Obstructive Lung Disease Recommendations in SPIROMICS. Ann Am Thorac Soc. 2019;16:200-8.

55. Suissa S, Patenaude V, Lapi F, Ernst P. Inhaled corticosteroids in COPD and the risk of serious pneumonia. Thorax. 2013;68:1029-36.

56. Liu VX, Winthrop KL, Lu Y, Sharifi H, Nasiri HU, Ruoss SJ. Association between Inhaled Corticosteroid Use and Pulmonary Nontuberculous Mycobacterial Infection. Ann Am Thorac Soc. 2018;15:1169-76.

57. Fishman A, Martinez F, Naunheim K et al. A randomized trial comparing lung-volume-reduction surgery with medical therapy for severe emphysema. N Engl J Med. 2003;348:2059-73.

58. Martinez FJ, Calverley PM, Goehring UM, Brose M, Fabbri LM, Rabe KF Effect of roflumilast on exacerbations in patients with severe chronic obstructive pulmonary disease uncontrolled by combination therapy (REACT): a multicentre randomised controlled trial. Lancet. 2015;385: 857-66. 